(C) 2007 IEEE. Personal use of this material is permitted. Permission from IEEE must be obtained for all other uses, in any current or future media, including reprinting/republishing this material for advertising or promotional purposes, creating new collective works, for resale or redistribution to servers or lists, or reuse of any copyrighted component of this work in other works. 


\title{
Control of Proton Exchange Membrane Fuel Cell Based on Fuzzy Logic
}

\author{
Yuedong Zhan ${ }^{1}$, Jianguo Zhu², Youguang Guo², Jianxun Jin $^{3}$ \\ 1. Kunming University of Science and Technology, Kunming 650051, China \\ E-mail: ydzhan@163.com \\ 2. Faculty of Engineering, University of Technology, Sydney (UTS), NSW 2007, Australia \\ E-mail: joe@eng.uts.edu.au, youguang@eng.uts.edu.au \\ 3. Center of Applied Superconductivity, University of Electronic Science and Technology of China, Chengdu, China
E-mail: jxjin@uestc.edu.cn
}

\begin{abstract}
This paper presents a control strategy suitable for hydrogen/air proton-exchange membrane fuel cells (PEMFCs), based on the process modeling using fuzzy logic. The control approach is tested using a PEMFC stack consisting of 32 cells with parallel channels. An optimal fuzzy-PI controller is designed to mainly control the hydrogen and air/oxygen mass flows, and auxiliary variables such as the temperature, pressure, humidity of the membrane, and proportion of stoichiometry. The fuzzy logic controller possesses many advantages over the PID controllers, such as a higher performance/cost ratio. It is shown experimentally that the optimal fuzzy-PI controller can improve the voltage and current performance of the system when the load changes.
\end{abstract}

Key Words: Proton Exchange Membrane Fuel Cell (PEMFC), System Control, Fuzzy Logic

\section{INTRODUCTION}

In the last decade, the performance of fuel cells has been greatly improved mainly thanks to the advancement of proton exchange membrane fuel cells (PEMFCs). A large amount of work was conducted by various researchers for predicting the performance, which is a key factor in the development of new applications. Unfortunately, the performance of a PEMFC is extremely difficult to model analytically, so empirical formulations are often used. Its performance depends on many variables, such as temperature, pressure, current density, and water content of the membrane. Many of these variables depend on each other yielding non-linearity in the performance models [1]. This makes the study on PEMFC control systems very difficult.

In this paper, a fuzzy logic controller with PI control loops is designed and implemented to directly control the $\mathrm{H}_{2}$ and air mass flows in a 500W PEMFC power system. The fuzzy-PI controller is used to automatically fine-tune the parameters of a conventional PI controller. Depending on the output voltage and current of the stack, the fuzzy controller constantly interprets the process reaction and calculates the optimal $\mathrm{P}$ and I gains. The output voltage of the PI controller directly regulates the flow rate of $\mathrm{H}_{2}$ and air. The experimental results demonstrate that the fuzzy-PI controller can improve the V-I performance of the PEMFC system, and maintain a constant output voltage of the PEMFC stack over a wide range of load.

A model-based control strategy would be desirable, which considers the transient response of the fuel cell with respect

This work is partly supported by the UTS Pro Vice Chancellor R\&D Seed Fund Grant. to load variation. With such a control strategy, the effort of adapting the model parameters for a specific design of the fuel cell and the peripheral components of the system could be minimized. A brief review on existing model-based control strategies for PEMFCs is presented in Section 2.

In practice, problems may occur during the operation of a PEMFC power system when the load varies. Typically, the load variation lasts milliseconds, followed by a peak power demand for a few seconds to minutes. When a load varies, for example, the output voltage and current of the PEMFC increase. The main purpose of the control strategy is to ensure constant output values and uninterrupted operation of the PEMFC stack for changing power demand.

In Section 3, the use of fuzzy methods for system control is discussed and our fuzzy-based control approach is presented. The set-up and experiments of a PEMFC system with the fuzzy-based control is described in Section 4.

\section{REVIEW ON MODEL-BASED CONTROL STRATEGIES}

The transient response of a PEMFC due to a load change is a complex phenomenon. The transient model has to account for the electrochemical reaction of the fuel and air, and multi-phase transport of the water and gas components. Moreover, heat and charge transports occur in the PEMFC.

Kuwata et al. [2] described a control method for a DC-DC converter and its characteristics. The converter can maintain the maximum fuel cell output to keep total efficiency high, and can achieve stable fuel cell operation even when the AC power fails or the load varies.

Ro and Rahman [3] developed a controller for a fuel cell power plant to assist the conventional generators for 
damping oscillation. The controller receives the grid bus voltage magnitude and system frequency variations, which are taken as the feedback inputs. A power conditioning subsystem fulfills the DC-AC power conversion by turning on and off switches according to a switching scheme.

Sedghisigarchi [4] analyzed the dynamics of distribution systems that contains fuel cells and the enhancement of the stability of these systems by controlling the fuel cells. The control loops through the power conditioning units were first explained using an one-machine infinite bus system.

Sakhare et al. [5] adopted a solid oxide fuel cell mathematical model, and designed a power condition unit for this solid oxide fuel cell and for fuel cells in general. The fuzzy logic control strategy is used in the design of the controllers for DC-AC and DC-DC converters. The output is converted to a controlled DC voltage by a control scheme that adjusts the duty ratio of the converter and also protects the fuel cell against sudden load variations and current reversal.

Iqbal [6] presented the dynamic modeling of various components of an isolated power system containing fuel cells. The selection of control strategies and design of controllers for the system is described. A software package, SIMNON ${ }^{\mathrm{TM}}$, is used for simulating this highly nonlinear system. A proportional-integral-differential (PID) type fuel cell controller is used to adjust the fuel $\left(\mathrm{H}_{2}\right)$ inlet and oxygen pressure to maintain a constant stack output voltage. The controller can compensate the voltage drop in the fuel cell stack caused by the load current variation. In the simulation, Iqbal used the PID type controller to control the fuel cell voltage by varying the $\mathrm{H}_{2}$ and $\mathrm{O}_{2}$ flow rates.

Based on their previous work, Khan and Iqbal [7] conducted a dynamic modeling and simulation of a small wind-fuel cell hybrid energy system. The system, however, has never been implemented.

Abtahi et al. [8] presented a control strategy for a fuel cell system based on a pressure regulator. Different pulsing profiles for the pulsed air source were investigated. The pulse amplitude, frequency and duty cycle were varied and their impact on the fuel cell power density was studied. The authors discussed the applicability of fuzzy logic to implement the control strategy. Pulsing of the air pressure cannot be applied in our fuel cell system because we use fans for the air supply.

\section{DESIGN OF FUZZY LOGIC CONTROLLER}

\subsection{Model of PEMFC System}

A PEMFC model used in this paper was developed by Balkin, Holland and Zhu [9]. In this model, the PEMFC stack terminal voltage, $V_{\text {stack }}$, is determined by subtracting the various voltage losses from the reversible voltage as

$$
V_{\text {stack }}=V_{\text {reversible }}-V_{\text {ohmLOSS }}-V_{\text {actLOSS }}-V_{\text {conLOSS }}
$$

where $V_{\text {reversible }}, V_{\text {ohmLOSs }}, V_{\text {actLoss }}$ and $V_{\text {conLOSS }}$ are the maximum theoretical voltage, ohmic voltage loss, activation voltage loss and concentration voltage loss, respectively.

Incorporated in these voltage loss terms is an internal current. These voltage losses result in an operating voltage that is less than the reversible voltage as shown in the typical polarization curve in Fig. 1.

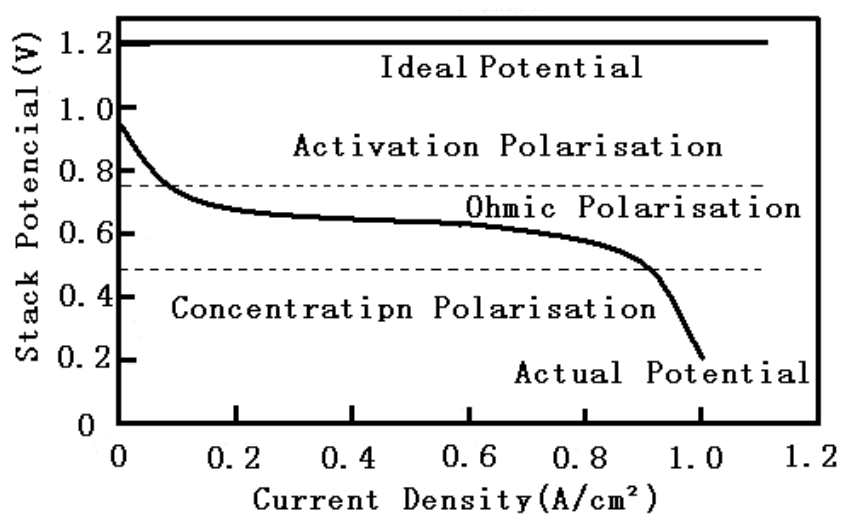

Fig. 1. Typical polarization curve of fuel cell stack

The reversible voltage at varying temperature and pressure can be expressed as

$$
\begin{aligned}
V_{\text {reversible }} & =N_{\text {cell }} V^{0}+\frac{R T}{2 F} \ln \left[\frac{p_{\mathrm{H}_{2}}^{*}\left(p_{\mathrm{O}_{2}}^{*}\right)^{\frac{1}{2}}}{p_{\mathrm{H}_{2} \mathrm{O}}^{*}} \times\left(\frac{1}{P_{0}}\right)^{\frac{1}{2}}\right] \\
& -N_{\text {cell }} \frac{\Delta \bar{S}_{298.15 K}}{2 F}(T-298.15)
\end{aligned}
$$

where $N_{\text {cell }}, V^{0}, R, T, F, P_{0}, \Delta \bar{s}_{298.15 K}$, and $p^{*}{ }_{m}$ are the number of cells in the PEMFC stack, reversible fuel cell voltage at the standard temperature and pressure (STP), universal gas constant, temperature of the PEMFC stack in $K$, Faraday's constant, standard pressure, change in the molar entropy at STP, and pressure of species $m\left(\mathrm{H}_{2}, \mathrm{O}_{2}\right.$, or $\mathrm{H}_{2} \mathrm{O}$ ), respectively.

With the pressure in atmosphere and using the standard values for the constants in (2), the reversible voltage can be reduced to

$$
\begin{aligned}
V_{\text {reversible }} & =N_{\text {cell }} \times 1.229+\left(4.308 \times 10^{-5}\right) T \times \ln \left[p_{\mathrm{H}_{2}}^{*}\left(p_{\mathrm{O}_{2}}^{*}\right)^{\frac{1}{2}}\right] \\
& -N_{\text {cell }} \times\left(8.453 \times 10^{-4}\right)(T-298 . .15)
\end{aligned}
$$




\subsection{Design of Fuzzy-PI Controller}

\subsubsection{Design Concept}

The fuzzy-PI controller, shown in Fig 2, uses the error signal and its change from the measured feedback data as the inputs. If the output signal describes the necessary difference toward the voltage and current output value, an intelligent fuzzy reasoning device is needed to build up the command variable value. That is to say, although the fuzzy-PI controller does not have a special operating point, the controller rules evaluate the difference between the measured values of voltage and current and the setting values, which is the error signal, and also evaluate the tendency of the error signal to determine whether to increase or decrease the control output variable. The absolute value of the command output variable is not influenced.

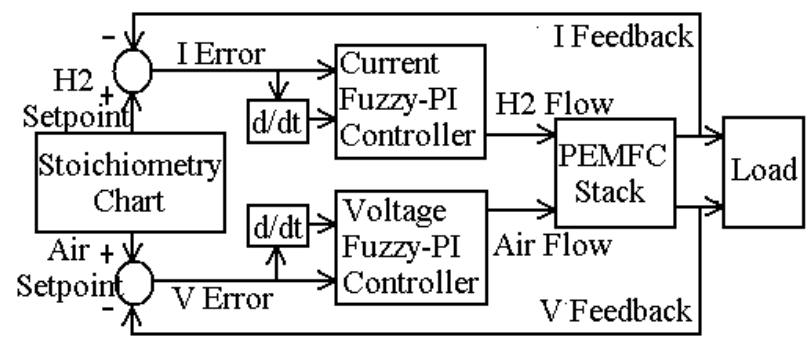

Fig. 2. Structure with Fuzzy-PI Controller

The advantage of a fuzzy-PI controller over a conventional PI controller is that it can implement nonlinear control strategies and that it uses linguistic rules. It is possible to consider only the error tendency when the error becomes small.

In this paper, in order to avoid the difficulty caused by that a large number of variables affect the performance of the PEMFC system and the use of a complex model, a fuzzy-PI controller based on PEMFC expert knowledge is proposed. The fuzzy-PI controller can produce a much better performance than a conventional PID controller.

The fuzzy-PI controller consists of five different steps and parts, including the definition of input-output variables of the controller, fuzzification, designing of fuzzy control rules, inference and defuzzification [10-14].

\subsubsection{Definition of Input-output Variables}

The air mass flow control loop is used as an example to show the design process of the fuzzy-PI controller as follows.

The controller input variables are the voltage error $e(k)$, and the change of error $c(k)$. The output variables are the optimal $P$ and $I$ gains of a subsequent PI controller device, one of them gives the proportional part $K$ as a function of $e(k)$ and $c(k)$, and the other gives the increment $\Delta T$, which is then integrated to provide the integral term $T$ of the PI controller. The error $e(k)$, change of error $c(k)$ and the output variable $u(k)$ of the controller are given by

$$
e(k)=V_{\text {setpoint }}-V_{\text {stack }}
$$

$$
\begin{gathered}
c(k)=e(k)-e(k-1) \\
u(k)=u(k-1)+K\left\{e(k)+\frac{1}{T} \sum_{i=1}^{k}\left[\frac{e(i)+e(i-1)}{2}\right] \Delta t\right\}
\end{gathered}
$$

\subsubsection{Fuzzification and Membership Function}

The triangular type membership function is chosen because of its linearity. The collections of the reference fuzzy set for the error, the change of error, and the control input are the same, but their scale factors are different. As shown in Fig 3, seven fuzzy subsets, i.e. positive big (PB), positive medium (PM), positive small (PS), zero ( $\mathrm{ZE}$ ), negative small (NS), negative medium (NM), and negative big (NB), are used for the input and output variables $e(k), c(k), K$ and $T$.
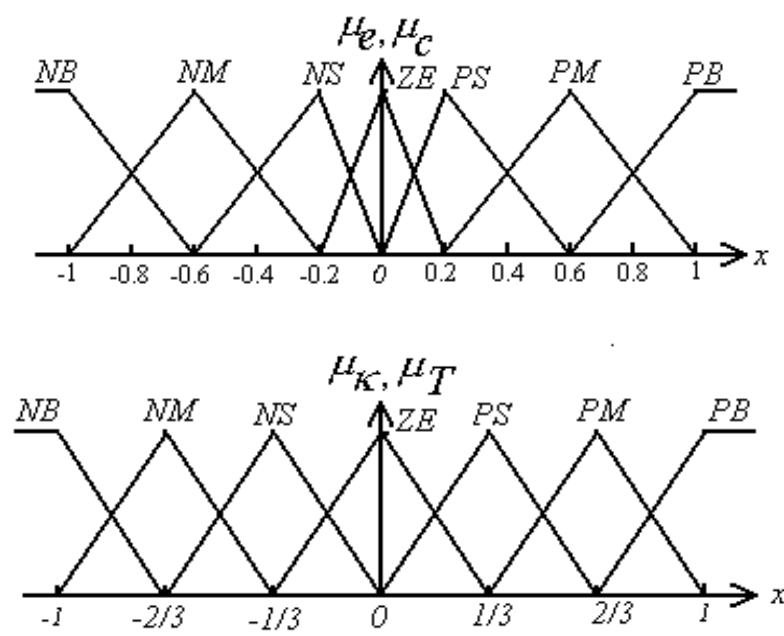

Fig. 3. Membership function for $e(k), c(k), K$ and $T$

\subsubsection{Design of Fuzzy Control Rules}

Fuzzy control rules are obtained from the behavior analysis of the PEMFC system. Because the rule-base represents the intelligence of the controller, the formulations should be carefully considered. Correct use of control laws according to the operating conditions can greatly improve the system stability. A fast response with a small overshoot for the PEMFC system can be achieved with proper handling of the proportional and integral parts.

The selected control rules or laws are described as follows:

1) Far from the voltage set point: When the output voltage is far from the set point, i.e. $e(k)$ is $\mathrm{PB}$ or $\mathrm{NB}$, the corrective action must be strong. This means that $K$ should be NB (or $\mathrm{PB}$ ) while $T$ should be zero (ZE), in order to prevent the continuous increase (or decrease) of integral term that would cause overshoots. In this case, the change of error plays little part.

The basic control rules are:

If $e(k)$ is $\mathrm{PB}$, then $K$ is $\mathrm{NB}$ and $T$ is $\mathrm{ZE}$;

If $e(k)$ is $\mathrm{NB}$, then $K$ is $\mathrm{PB}$ and $T$ is $\mathrm{ZE}$.

2) Close to the voltage set point: In this region, the change of error must be properly taken into account in order to ensure stability and speed of response. The goal of the 
fuzzy controller is to achieve a satisfactory dynamic performance with small sensitivity to parameter variations.

The control rules are:

If both $e(k)$ and $c(k)$ are $\mathrm{ZE}$, then $K$ and $T$ are $\mathrm{ZE}$;

If both $e(k)$ and $c(k)$ is negative, $K$ and $T$ are negative;

If both $e(k)$ and $c(k)$ is positive, $K$ and $T$ are positive.

According to these criteria, the rule sets are derived as shown in Table 1 and Table 2.

Table 1: Rule Table for $P$

\begin{tabular}{|c|c|c|c|c|c|c|c|}
\hline$e_{c(k)}^{(k)}$ & NB & NM & NS & ZE & PS & PM & PB \\
\hline PB & NB & PS & PM & PM & PB & PB & PB \\
\hline PM & NB & ZE & PS & PM & PM & PB & PB \\
\hline PS & NB & NS & ZE & PS & PM & PB & PB \\
\hline ZE & NB & NM & NS & ZE & PS & PM & PB \\
\hline NS & NB & NB & NM & NS & ZE & PS & PB \\
\hline NM & NB & NB & NM & NM & NS & ZE & PB \\
\hline NB & NB & NB & NB & NM & NM & NS & PB \\
\hline
\end{tabular}

Table 2: Rule Table for $T$

\begin{tabular}{|c|c|c|c|c|c|c|c|}
$\overbrace{c(k)}^{(k)}$ & NB & NM & NS & ZE & PS & PM & PB \\
\hline PB & ZE & ZE & PM & PB & PM & ZE & ZE \\
\hline PM & ZE & ZE & PS & PM & PS & ZE & ZE \\
\hline PS & ZE & NS & ZE & PS & PM & ZE & ZE \\
\hline ZE & ZE & NM & NS & ZE & PS & PM & ZE \\
\hline NS & ZE & ZE & NM & NS & ZE & PS & ZE \\
\hline NM & ZE & ZE & NS & NM & NS & ZE & ZE \\
\hline NB & ZE & ZE & NM & NB & NM & ZE & ZE \\
\hline
\end{tabular}

\subsubsection{Inference}

There are various ways in which the observed input values can be used to identify which rules should be used to infer an appropriate fuzzy control action. The fuzzy inference methods are MAX-MIN fuzzy inference reasoning, MAX-PRODUCT inference reasoning, and SUM-PRODUCT fuzzy reasoning.

A basic and simple inference method, MAX-MIN fuzzy inference, is employed in this paper. One of the rules is expressed by

Rule $i$ : If $e$ is $E i$ and $c$ is $C i$, then $P$ (or $T$ ) is $P i$ (or $T i$ )

$i=1, \cdots, n$,

The membership of the inferred consequence $P$ (or $T$ ) is point-wise, given by

$$
\mu_{P}(z)=\vee_{i=1}^{n}\left(\left(\mu_{E_{i}}(e) \wedge \mu_{C_{i}}(c)\right) \wedge \mu_{P_{i}}(e, c)\right)
$$

\subsubsection{Defuzzification}

Defuzzification is the process of mapping from a space of inferred fuzzy control actions to a space of non-fuzzy control actions. A defuzzification strategy aims to produce a non-fuzzy control action that best represents the possibility distribution of the inferred fuzzy control actions. In real-time implementation of fuzzy logic control, the commonly used defuzzification strategies include the mean of maximum (MOM), the center of maximum (COM), the center of area (COA) and the center of gravity (COG).
The COA is selected for the defuzzification process in this paper. The inferred values $P^{*}$ (or $T^{*}$ ) of the control action corresponding to the values $e(k)$ and $c(k)$ are obtained by

$$
P^{*}=\frac{\sum_{i=1}^{n} \mu_{P}\left(P_{i}\right) P_{i}}{\sum_{i=1}^{n} \mu_{P}\left(P_{i}\right)}
$$

where $P i$ is the singleton value of the fuzzy output variable using the $i$-th rule.

\section{TEST SYSTEM AND RESULTS OF PEMFC FUZZY CONTROL}

A testing PEMFC power system was constructed at UTS. The design of the prototype device has been investigated by the authors with the help of the description manual of the apparatus provided by the manufacturer. The evaluation of the functionality and effectiveness of the device was based on the experimental data of the 32-cell, 500W stack, which will be used for the stack performance testing, model and control evaluation, and investigation of new fuel cell technology. This apparatus has been designed to measure and basically control the mass flow rate, pressure, temperature, relative humidity of the hydrogen and air, and inlet temperature and outlet temperature of the water-cooling. Additionally, the test apparatus can measure the stack voltage and current, and coolant water temperature change across the stack.

The PEMFC test system is comprised of a PEMFC module and a control software. The module consists of a PEMFC stack, water-cooling components, air-cooling, hydrogen humidification filtering and temperature monitoring. There are three gases used to operate this system: hydrogen, nitrogen and oxygen. The control software is used to control the whole process.

The proposed fuzzy-PI logic controller is tested and implemented in the UTS PEMFC power system. Based on the control software LabVIEW ${ }^{\mathrm{TM}}$, the control interface is designed and shown in Fig 4.

The output voltage and current are set according to the stoichiometry chart of the PEMFC stack. Some experimental results are given in Fig. 5.

The experimental results reveal that while the PEMFC stack works in the open-loop state, according to the stoichiometry chart, after the $\mathrm{H}_{2}$ and air flow values have been set, the output voltage and current values will change when load and other conditions change. Once the fuzzy-PI controller is introduced, the output voltage and current characteristic could be adjusted to the desired values. The characteristics of fuzzy-PI controller are better than those of the PID controller. Its overshoot is smaller while the settling time is similar. 


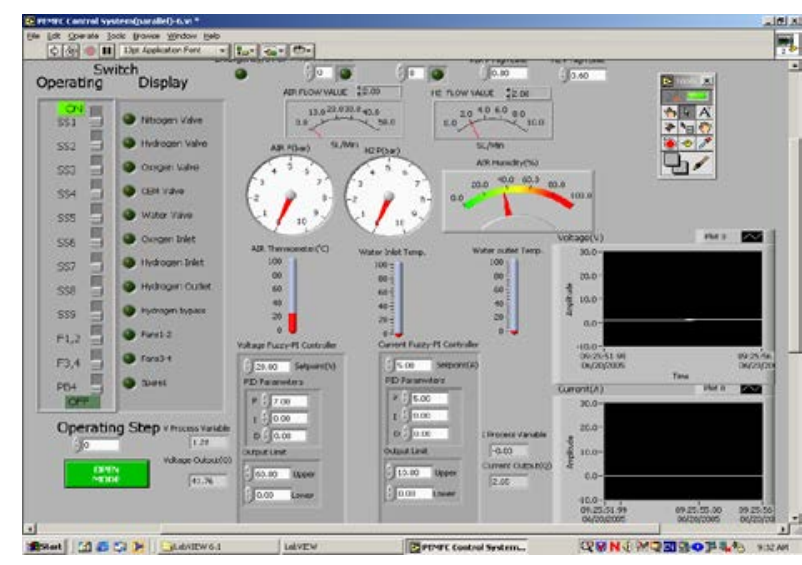

Fig. 4. Control interface of the PEMFC system

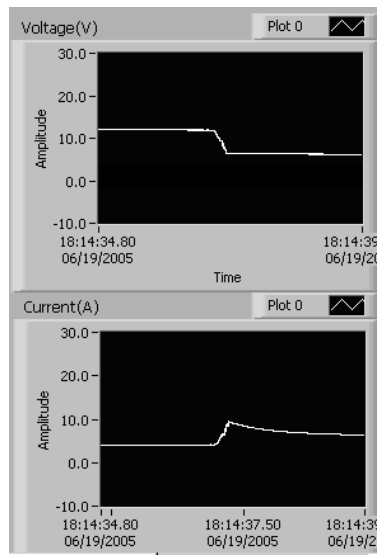

(a)

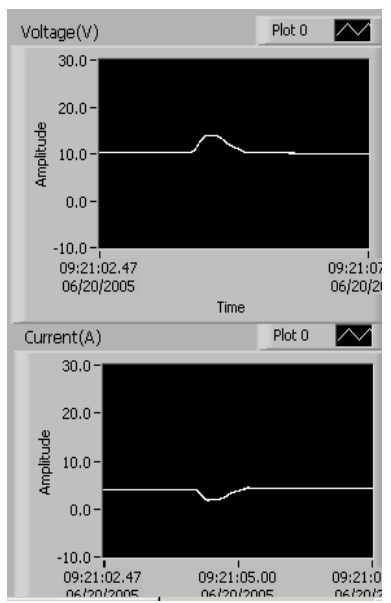

(c)

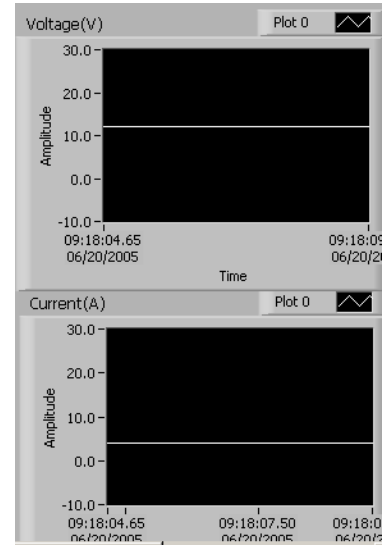

(b)

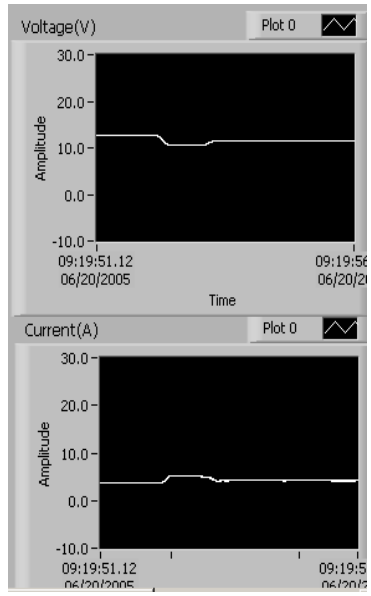

(d)
Fig. 5. Experimental results of output voltage and current when load changes: (a) Open-loop dynamic response; (b) Closed-loop static response; (c) PID control response; and (d) Fuzzy-PI dynamic response.

\section{CONCLUSION}

A fuzzy-PI controller for PEMFC power systems based on double closed-loop control is presented. Compared to the open-loop and standard PI control, the new controller can improve significantly the load performance of the fuel cell stack. Both the theoretical and experimental results have proved that the fuzzy control scheme can work well without using an accurate mathematical model. A major advantage of the fuzzy-PI controller over a conventional PI controller is its capability to implement nonlinear control strategies by using linguistic rules. It is possible to consider only the error tendency when the error becomes small. With fuzzy logic controllers, the experience and the knowledge obtained by the supervising operators can be used to form fuzzy rules, which are important in developing a fuzzy logic controller. The effectiveness of the proposed intelligent fuzzy controller has been verified by experimental results of a PEMFC power system.

\section{REFERENCES}

[1] G. Hoogers, Fuel Cell Technology Handbook, CRC Press, New York, USA, 2003.

[2] Y. Kuwata, T. Babasaki, M. lwasawaf and T. Koyashikit, Input current controlled DC interconnection converter for fuel cell systems, Proceedings of $16^{\text {th }}$ International Conference on Telecommunications Energy, 375-380, 1994.

[3] K. Ro and S. Rahman, Control of grid-connected fuel cell plants for enhancement of power system stability, Renewable Energy, Vol.28, 397-407, 2003.

[4] K. Sedghisigarchi, Dynamic and transient analysis of power distribution systems with fuel cells - Part II: Control and stability enhancement, IEEE Trans. on Energy Conversion, Vol.19, No.2, 429-433, 2003.

[5] A. R. Sakhare, A. Davari, and A. Feliachi, Control of solid oxide fuel cell for stand-alone and grid connection using fuzzy logic, in Proceedings of the $36^{\text {th }}$ Southeastern Symposium on System Theory, 551-555, 2004.

[6] M. T. Iqbal, Modeling and control of a wind fuel cell hybrid energy system, Renewable Energy, Vol.28, 223-237, 2003.

[7] M. J. Khan and M. T. Iqbal, Dynamic modeling and simulation of a small wind-fuel cell hybrid energy system, Renewable Energy, Vol.30, 421-439, 2005.

[8] A. Abtahi, A. Zilouchian, and M. Fuchs, Design and implementation of a hierarchical control strategy for proton exchange membrane fuel cells, in Proceedings of the Conference on Decision and Control, Vol. 37, Tampa, Florida, 461-462,1998.

[9] A. R. Balkin, B. J. Holland, and J. G. Zhu, Modeling polymer electrolyte membrane fuel cells, in Proceedings of Australasian Universities Power Engineering Conference, Melbourne, Australia, 2002

[10] National Instruments ${ }^{\text {TM }}$, PID Control Toolset User, November 2001 Edition, available online: http://digital.ni.com/public.nsf/.

[11] H. X. Li, P. L. Chen, and H. P. Huang, Fuzzy Neural Intelligent Systems Mathematical Foundation and the Applications in Engineering, CRC Press LLC, New York, USA, 2001.

[12] Y. H. Kim and S. S. Kim, An electrical modeling and fuzzy logic control of a fuel cell generation system, IEEE Trans. on Energy Conversion, Vol.14, No.2, 239-244, 1999.

[13] P. Mattavelli, L. Rossetto, G. Spiazzi, and P. Tenti, General-purpose fuzzy controller for DC-DC converters, IEEE Trans. on Power Electronics, Vol.12, No.1, 79-86, 1997.

[14] T. Gupta, R. R. Boudreaux, R. M. Nelms, and J. Y. Hung, Implementation of a fuzzy controller for DC-DC converters using an inexpensive 8-b microcontroller, IEEE Trans. on Industrial Electronics, Vol.44, No.5, 661-669, 1997. 